\title{
О.В. Россолов
}

Харківський начіональний університет міського господарства імені О.М. Бекетова, Украӥна

\section{ДОСЛІДЖЕННЯ ЛАТЕНТНОГО ПОПИТУ НА ПОСЛУГУ КРАУДШИПІНГУ 3 ВИКОРИСТАННЯМ ФАКТОРНОГО АНАЛІЗУ}

В статті представлено результати експериментального дослідження по визначенню латентного попиту на послугу краудшипінгу при доставціі онлайн замовлень продуктів харчування з супермаркетів. Для визначення базових атрибутів латентного попиту застосовано факторний аналіз. Результати дослідження трунтуються на анкетуванні 250 осіб в місті Харків. Встановлено часові, просторові та екологічні атрибути як значущі, щзо необхідн враховувати при впровадженні сервісу краудшипінг.

Ключові слова: електронна комериія, система доставки, краудшипінг, факторний аналіз.

\section{Постановка проблеми}

Пандемія Covid-19 прискорила процес інтеграції електронної комерції в систему постачань в сучасних містах. В ряді досліджень встановлено, що впровадженні карантинні обмеження сумісно з неясністю щодо тривалості пандемії, призвели до суттєвої трансформації покупної поведінки кінцевих споживачів з магазин-орієнтованої до онлайн-орієнтованої [1-3]. В таких умовах кількість онлайн замовлень зросла в декілька разів за досить короткий проміжок часу, що призвело до збоїв в системі адресних онлайн постачань. Особливо гостро це знайшло свій прояв в доставці продуктів харчування, для яких канал онлайн покупок слабо використовувався до пандемії Covid19 [4].

Одним з можливих шляхів вирішення проблеми виконання онлайн замовлень продуктів харчування 3 адресною доставкою є впровадження системи краудшипінгу. В ряді країн Західної Європи вже проводяться дослідження в даному напрямку, які направлені на економічне обгрунтування доцільності впровадження даного сервісу. Безумовно це є актуальним напрямком дослідження, яке потребує глибокої проробки для ефективного впровадження системи краудшипінгу. Але наряду з економічним обгрунтуванням, особливу увагу заслуговує питання визначення попиту на дану послугу та встановлення категорії громадян, які готові користуватися системою краудшипінгу. Враховуючі необхідність певної соціальної активності та довіри між замовником послуги та іiї надавачем, готовність українців користуватися даною послугою $є$ над актуальним питанням, яке потребує глибокого вивчення.

Беручи до уваги, що в даний час система краудшипінгу майже не розвинена в Україні, то попит на послуги по доставці продуктів харчування на базі парадигми довіри можна вважати латентним.

\section{Аналіз останніх досліджень і публікацій}

Питання впровадження краудшипінгу для міських постачань стало актуальним 3 початком імплементації планів сталого розвитку міст. Краудшипінг в таких умовах розглядається як інструмент адаптації системи постачання до транспортних умов в першу чергу в крупних та найкрупніших містах, в яких транспортна складова оказує суттєвий негативний вплив на навколишнє середовище. Виходячи 3 цієї парадигми група дослідників на чолі проф. Гатта та проф. Маркуччі [5] розглянула можливість впровадження системи доставки останньої милі на основі краудшипінгу в місті Рим (Італія). Система метрополітену розглядалась як елемент транспортного забезпечення поставки онлайн замовлень кінцевим споживачам. Особливістю дослідження був комплексний розгляд проблеми побудови системи доставки, а саме, проведення аналізу попиту, як на постачання, так і на обслуговування. В якості методології дослідження застосовано теорію максимізації випадкової корисності.

Питання економічного обгрунтування доцільності впровадження системи краудшипінгу займає особливе місце в рамках досліджень цього напрямку. Так в [6] розглянуто економічні компоненти системи забезпечення краудшипінгу в США. Проведено комплексний аналіз результатів опитування 549 осіб щодо їх готовності надавати послуги краудшипінгу. В якості аналізованих атрибутів розглядались: граничний час виконання замовлення, гранична плата за надання послуги та дні тижня, в які люди готові надавати послуги краудшипінгу.

В роботі [7] приділено увагу питанню оцінки плати за послугу краудшипінгу на основі розроблених варіантів маршрутів руху надавачів послуги. Розглянуто декілька сценаріїв формування доходу, отриманого від надання послуги краудшипінгу для 
оцінки ефекту «надлишку» (surplus). Слід відзначити, що обмеженням даного дослідження є розгляд лише велосипедного виду транспорту у якості системи транспорту для виконання доставки. Поряд 3 цим в якості надавача послуги розглядається аналог кур'єрської служби, а не звичайні мешканці міст.

Аналогічно 3 [7] в [8] розглядається питання впровадження системи краудшипінгу на базі велосипедного транспорту. В досліджені розглянуто обидві сторони системи доставки: попит та забезпечення доставки. Статистична значимість атрибутів кожної підсистеми визначалися на основі теорії максимізації випадкової корисності. Функція корисності для попиту представлена вартістю та часом доставки, екологічним фактором, часовим вікном доставки та рейтингом кур'єрської служби. В свою чергу функція корисності для системи транспортного забезпечення формалізована через день тижня, компенсацію за надання послуги, вагу пакунку та екологічну складову. На основі двох функцій корисності формалізовано умову пошуку вартості послуги на основі балансу між попитом та пропозицією.

\section{Формальна постановка завдання дослідження}

Метою даного дослідження є оцінка визначення характеристик латентного попиту на послугу краудшипінгу при онлайн покупці продуктів харчування. Об'єктом дослідження є процес транспортно-логістичного обслуговування кінцевих споживачів на основі послуги краудшипінгу. В якості предмету дослідження розглядаються характеристики латентного попиту на послугу краудшипінгу при онлайн покупці продуктів харчування кінцевими споживачами.

\section{Розробка методики оцінки латентного попиту на послугу краудшипінгу}

При оцінці вподобань кінцевих споживачів щодо вибору способу покупки та доставки продуктів харчування особливу увагу слід приділяти оцінці латентних змінних, які не спостерігаються безпосередньо під час натурних обстежень за поведінкою людей. Фактично вони є випадковими змінними, які, як правило, формалізуються через структурне рівняння $[9,10]$ :

$$
\begin{gathered}
L V_{q z}=h\left(x_{q} \mid \boldsymbol{\beta}_{q}^{s}\right)+\boldsymbol{\psi}_{L V_{q z}} \\
h\left(x_{q} \mid \boldsymbol{\beta}_{q}^{s}\right)=\beta_{0}^{s}+\sum_{k=1}^{K_{s}} \beta_{k}^{s} \cdot x_{k}, \\
\psi_{L V_{q z}}=f\left(0, \sigma_{L V_{q z}}^{2}\right),
\end{gathered}
$$

де $L V_{q z}$ - структурне рівняння для латентної змінної z для $q$ кінцевого споживача; $h\left(x_{q} \mid \boldsymbol{\beta}_{q}^{s}\right)$ - детермінована складова структурного рівняння; $\boldsymbol{\psi}_{L V_{q z}}$ - стохастична складова структурного рівняння, яка розподілена за нормальним законом з математичним очікуванням рівним нулю та дисперсією $\sigma_{L V_{q z}}^{2}$, яка дорівнює одиниці; $\boldsymbol{\beta}_{q}^{s}-$ вектор параметрів моделі, який формується вектором атрибутів $x_{q}$; $\beta_{0}^{s}$ - вільний член моделі детермінованої складової структурного рівняння; $\beta_{k}^{s}-$ специфічні параметри моделі $h\left(x_{q} \mid \boldsymbol{\beta}_{q}^{s}\right)$ для певного $k$-го атрибуту; $x_{k}-$ атрибут моделі.

Латентні змінні $L V_{q z}$ формуються на основі непрямих оцінок, які проводяться під час обстежень за покупною активністю кінцевих споживачів. Ці оцінки можуть проводитися за декількома варіантами [11]:

- постановка прямих питань 3 необхідністю дати оцінку ступеню почуттів респондента стосовно певного процесу або явища із застосуванням, наприклад, десяти бальної шкали (неперервне оцінювання);

- постановка прямих питань з їх оцінкою за шкалою Лайкерта [12];

- постановка непрямих питань, що характеризують позитивні та негативні ствердження стосовно певного процесу чи явища з їх оцінкою за шкалою Лайкерта та проведенням факторного аналізу.

В рамках поставленої задачі визначення потенційних клієнтів сервісу краудшипінг, який ще не впроваджено на території України, пропонується обрати третій підхід щодо оцінки латентних змінних, який базується на факторному аналізі. В таких умовах, взаємозв'язок між латентними змінними $L V_{q z}$ та шкалою замірів (вимірювання) формалізується наступним чином:

$$
I_{q w}=\bar{I}_{w}+\tau_{I_{W}} \cdot L V_{q z}+v_{q w},
$$

де $\bar{I}_{w}$ - середнє значення оцінки за п'яти бальною шкалою Лайкерта; $\tau_{I_{W}}-$ коефіцієнт вимірювання латентної змінної $L V_{q z}$, який формується на основі факторних навантажень для оцінюваного ствердження $w ; \boldsymbol{v}_{q w}$ - стохастична складова вимірюваного рівняння; $W$-кількість оцінюваних стверджень.

$$
\boldsymbol{v}_{q w}=f\left(0, \sigma_{I_{W}}^{2}\right)
$$

$$
\text { де } \sigma_{I_{W}}^{2}-\text { дисперсія } I_{W} \text {. }
$$


Для проведення оцінки латентних змінних за методологіє факторного аналізу сформовано низку стверджень, які повинні будуть оцінені кінцевими споживачами за п’яти бальною шкалою Лайкерта. Сформовані ствердження представлені нижче.

1. Вартість доставки занадто висока для мене.

2. Доставка додому економіть мій час.

3. Покупки в Інтернеті занадто складні для мене.

4. Я люблю гуляти по магазинах.

5. Ризик придбання неякісного товару є основною причиною покупок у магазині для мене.

6. Гнучкість при здійсненні доставки додому (час доставки, місце тощо) важлива для мене.

7. Я стурбований(а) безпекою та ијілісністю товару при доставиі.

8. Я надаю перевагу сочіальним контактам при покупках у магазинах.

9. Покупки у магазинах дуже втомлюють мене.

10. Я довіряю тільки офіиіійним представникам постачання послуг.

11. Крауд перевізник є більш надійний, бо він особисто відповідає за мій товар.

12. Краудшипінг дозволяє скоротити викиди та зменшити забруднення повітря.

13. Мене не турбує забруднення атмосфери.

14. Я подорожую екологічно для навколишнього середовищча.

15. С більи важливіші проблеми, ніж охорона навколишнього середовищуа.

\section{Проведення факторного аналізу характеристик попиту на послугу краудшипінгу в Україні}

Опитування потенційних користувачів системи «Краудшипінг» проводилось в місті Харків в період 3 грудня 2020 по лютий 2021. В якості каналу розповсюдження анкет у формі Google Form було обрано електронні соціальні мережі. По-перше, в останні роки даний канал збору даних все більше застосовується дослідницькими групами 3 високою ефективністю. По-друге, в умовах пандемії актуальність застосування даного каналу зросла. В результаті анкетування було охоплено 250 кінцевих споживачів, які сформували вибіркову сукупність.

Отримані результати є основою для проведення факторного аналізу з метою виявлення латентних параметрів попиту на послугу краудшипінгу. Факторний аналіз проводиться за допомогою програмного продукту Statistica 7.0. Першим кроком $\epsilon$ побудова розподілу характеристичних чисел (eigenvalues), який визначає кількість факторів. При цьому матриця не $є$ ротабельною, а мінімальне значення eigenvalue приймається рівнем нулю для охоплення всього можливого діапазону. Графік характеристичних чисел (eigenvalues) представлено на рис. 1.

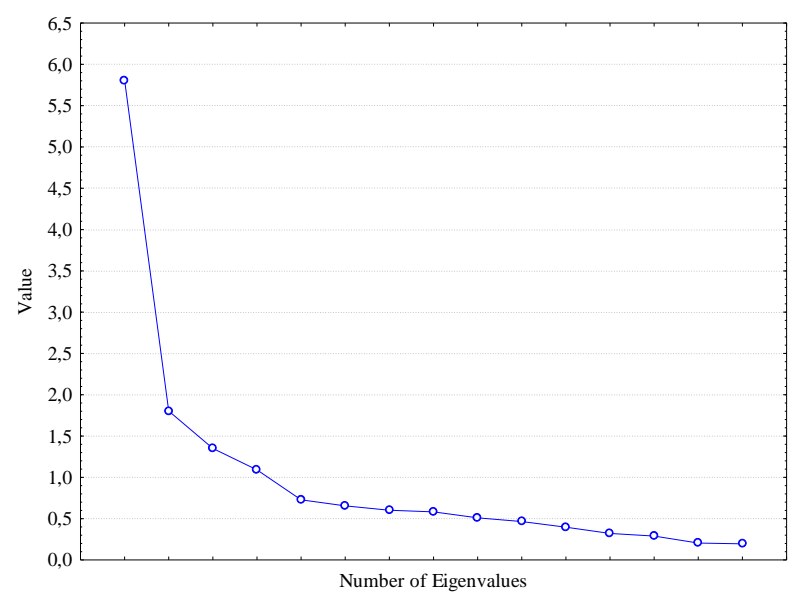

Рис. 1. Графік характеристичних чисел

Згідно критерію Кайзера [13] кількість факторів складає чотири, так як для усіх інших факторів значення характеристичних чисел менше одиниці (рис. 1). Таким чином, необхідно оцінити факторні навантаження (loadings) з умовами ротації факторів (Varimax raw). В якості гранично мінімального завантаження обрано рівень 0.5. Результати оцінки факторних навантажень представлено на рис. 2.

\begin{tabular}{||l|r|c|r|r||}
\hline Variable & \multicolumn{1}{|c|}{$\begin{array}{c}\text { Factor } \\
\text { Vactor }\end{array}$} & $\begin{array}{c}\text { Factor } \\
2\end{array}$ & \multicolumn{1}{c|}{ Factor } \\
\hline 1 & 0,395372 & 0,073961 & 0,582933 & 0,218230 \\
\hline 2 & 0,659736 & 0,111283 & 0,362478 & $-0,082394$ \\
\hline 3 & 0,301647 & 0,080679 & 0,110761 & 0,802064 \\
\hline 4 & $-0,022582$ & 0,299870 & 0,587307 & 0,551791 \\
\hline 5 & 0,227548 & 0,141818 & 0,702188 & 0,237151 \\
\hline 6 & 0,705516 & 0,096720 & 0,144018 & 0,102964 \\
\hline 7 & 0,680274 & 0,063460 & 0,339962 & 0,111393 \\
\hline 8 & 0,050191 & 0,258074 & 0,173794 & 0,852585 \\
\hline 9 & 0,556395 & 0,251427 & $-0,404429$ & 0,394515 \\
\hline 10 & 0,160254 & 0,666341 & 0,198509 & 0,239097 \\
\hline 11 & 0,803332 & 0,175398 & 0,130086 & 0,107841 \\
\hline 12 & 0,743222 & 0,196169 & $-0,009801$ & 0,256723 \\
\hline 13 & 0,124577 & 0,898134 & 0,054816 & 0,115639 \\
\hline 14 & 0,600268 & 0,212874 & $-0,056828$ & 0,458733 \\
\hline 15 & 0,164065 & 0,836371 & 0,057647 & 0,189204 \\
\hline
\end{tabular}

Рис. 2. Результати оцінки факторних навантажень

Для формалізації визначених факторів необхідно поєднати виявлені факторні навантаження (рис. 2) та 15 стверджень, які демонструють відношення респондентів до різних елементів системи постачання. Слід відмітити, що для ідентифікації фактору кожному ствердженню необхідно надати характеристику, тобто приналежність до певної складової. Наприклад, деякі ствердження можуть відбивати екологічні складові, потребу в соціальних контактах та інше. В результаті аналізу взаємозв'язку між 
факторними навантаженнями та факторами встановлено наступне:

- фактор №1 детермінований сьома ствердженнями, які відображають бажання кінцевих споживачів економити час завдяки онлайн замовленням, виконанню доставки 3 гнучким графіком та високою надійністю. Поряд 3 цим високі факторні навантаження отримано для екологічних складових, що відповідають стурбованості кінцевих споживачів щодо негативного впливу транспорту на навколишнє середовище, яке буде відбуватися при використанні комерційних перевізників для виконання онлайн замовлень;

- фактор №2 характеризується навантаженнями екологічної байдужості та фіксацією кінцевих споживачів на власних потребах;

- фактор №3 відбиває орієнтацію кінцевих споживачів на покупки продуктів харчування в фізичних магазинах, що обумовлено задоволенням від їх відвідування (ствердження №4). Також слід відмітити ствердження №1 та №5, які вказують на відмову деяких кінцевих споживачів користуватись онлайн каналом покупки в зв'язку з неможливістю перевірити якість товару перед його придбанням та неготовністю сплачувати за доставку продуктів харчування;

- фактор №4 характеризує перевагу соціальних контактів під час відвідування фізичних магазинів в порівнянні зі складністю користування онлайн сервісів.

Слід відзначати, що на рис. 2 в якості 15 змінних виступають ствердження, які були оцінені за п'яти бальною шкалою Лайкерта учасниками анкетування. Згідно проведеної оцінки з чотирьох виявлених факторів фактор №1 формує 38.72 відсотки варіації усіх даних, що є високим значенням. Відповідно, фактор №2 формує 12.02 відсотки варіації даних, фактор №3 - 8.99 відсотків та фактор №4 - 7.27 відсотків.

На основі характеристичного опису результатів факторного аналізу можна формалізувати кожен з чотирьох факторів наступним чином:

- фактор №1 - «ProCrowdShoppers», який характеризує людей готових користуватися новим сервісом постачань продуктів харчування на основі краудшипінгу зі сталою екологічною компонентою;

- фактор №2 - «Con_sustainable_shoppers», який характеризує групу людей, які не турбуються проблемами екології і власні потреби вони ставлять вище ніж проблеми суспільства;

- фактор №3 - «Store_lovers», який характеризує людей схильних до використання «класичного» каналу покупок продуктів харчування, а саме - «фізичного магазину»;

- фактор №4 - «Windows_shoppers», який описує людей, що відвідують фізичні магазини в першу чергу заради фізичних контактів та отримання насолоди від знаходження в покупному просторі.

\section{Висновки}

На основі проведеного дослідження можна зробити наступні висновки:

1. Дослідження латентного попиту на основі факторного аналізу дозволяє встановити ключові характеристики послуги краудшипінгу, які $\epsilon$ значущими для потенційних кінцевих споживачів. Інформація про ці атрибути $є$ важливою для розробників мобільних додатків та модераторів послуги краудшипінгу в країні впровадження, що дає можливість ефективного запуску нового сервісу сталих постачань.

2. Серед факторних атрибутів, які описують схильність кінцевих споживачів користуватися послугою краудшипінгу, встановлено:

- бажання кінцевих споживачів економити час завдяки онлайн замовленням;

- виконання доставки 3 гнучким графіком та високою надійністю;

- екологічна складова, що відповідає стурбованості кінцевих споживачів щодо негативного впливу транспорту на навколишнє середовище.

3. Встановлений латентний фактор краудшипінгу формує 38.72 відсотки варіації усіх даних, що $\epsilon$ найбільшим показником серед виявлених чотирьох факторів. Це дає можливість стверджувати про великий потенціал впровадження послуги краудшипінгу для доставки продуктів харчування в Україні.

4. Реалізований факторний аналіз є основою для проведення подальших досліджень 3 оцінки латентного попиту на послугу краудшипінгу продуктів харчування. Подальше дослідження буде спрямовано на розробку моделі дискретного вибору каналів постачання продуктів харчування у містах.

\section{References}

1. Grashuis, J., Skevas, T., \& Segovia, M.S., 2020. Grocery Shopping Preferences during the COVID-19 Pandemic. Sustainability, 12, 5369. $10 \mathrm{p}$.

2. Hall, M. C., Prayag, G., Fieger, P., Dyason, D., 2020. Beyond panic buying: consumption displacement and COVID-19. Journal of Service Management, $16 \mathrm{p}$.

3. Zhang, W., Leng, X., Liu, S., 2020. Research on mobile impulse purchase intention in the perspective of system users during COVID-19. Personal and Ubiquitous Computing, 9 p. 4. Rossolov, A., Rossolova, H., Holguin-Veras, J., 2021. Online and In-Store Purchase Behavior: Shopping Channel Choice in a Developing Economy. Transportation, 37 p.

5. Gatta, V., Marcucci, E., Nigro, M., Serafini, S., 2019. Sustainable urban freight transport adopting public transport-based crowdshipping for B2C deliveries. European Transport Research Review, 11.13, 14 p.

6. Le, T.V., Ukkusuri, S.V., 2019. Crowd-shipping services for last mile delivery: Analysis from American survey data. Transportation Research Interdisciplinary Perspectives, 1, 100008, 12 p.

7. Le, T.V., Ukkusuri, S.V., Xue, J., Van Woensel, T., 2021. Designing pricing and compensation schemes by integrating 
matching and routing models for crowd-shipping systems. Transportation Research Part E, 149, 102209, 20 p.

8. Wicaksono, S., Lin, X., Tavasszy, L.A., 2021. Market potential of bicycle crowdshipping: A two-sided acceptance analysis. Research in Transportation Business \& Management, paper in press.

9. Atasoy, B., Glerum, A., Bierlaire, M., 2011. Mode choice with attitudinal latent class: a swiss case-study, Proceedings of the Second International Choice Modeling Conference, Leeds, UK.

10. Bolduc, D., Álvarez-Daziano, R. 2009. On Estimation of Hybrid Choice Models. In Choice Modelling: The State-of-theArt and the State-of-Practice, Proceedings from the Inaugural International Choice Modelling Conference (S. Hess and A. Daly, eds.), Emerald Group Publishing, Bingley, United Kingdom, $30 \mathrm{p}$.

11. Bierlaire, M., 2018. Estimating choice models with latent variables with PandasBiogeme. Report TRANSP-OR 181227 , Transport and Mobility Laboratory, Ecole Polytechnique $\mathrm{F}^{\prime}$ ed'erale de Lausanne, $70 \mathrm{p}$.
12. Likert, R., 1932. A technique for the measurement of attitudes. Archives of psychology, 140, 1-55.

13. Kaiser, H.F., 1958. The Varimax Criterion for Analytic Rotation in Factor Analysis. Psychometrika, 23(3), 187-200.

Рецензент: д-р техн. наук, професор Н.У. Гюлєв, Харківський національний університет міського господарства імені О. М. Бекетова, Україна.

Автор: РОССОЛОВ Олександр Вікторович кандидат технічних наук, доцент, доцент кафедри транспортних систем і логістики

Харківський національний університет міського господарства імені О.М. Бекетова

E-mail-rossolovalex@gmail.com

ID ORCID: https://orcid.org/0000-0003-1495-0173

\title{
EXPLORATION OF LATENT DEMAND FOR CRAUDSHIPPING SERVICE USING FACTOR ANALYSIS
}

\author{
A. Rossolov
}

O.M. Beketov National University of Urban Economy in Kharkiv, Ukraine

This paper presents the experimental study results on exploring the latent demand for crowdshipping service. Factor analysis has been used as the key methodology to reveal the basic attributes of the demand. Given the absence of crowdshipping-based services in Ukraine we focused on evaluation the intentions of online shoppers to use the proposed delivery system. To do this we used five-point Likert scale to evaluate 15 statements in regard to pros and cons attitudes towards crowdshipping. Pros online shopping behavior has been considered as the basic component to promote the crowdshipping service. In this case the formed statements for pros crowdshipping have been described the time, cost, ecology, flexibility of the proposed delivery service. In turn the anti-online shopping intentions have been presented with enjoy of physical stores visiting, social interaction needs, browsing the products and etc. As the results of the factor analysis, we revealed four factors and one of them has been identified as "ProCrowdShoppers". This factor covers $38 \%$ of variance for all data of the study. Such a high value allows us to make conclusion about high potential of crowdshipping deployment in Ukraine. The second factor has been identified as "Con_sustainable_shoppers" which covered people that do not care about ecology during the delivery fulfilment. This group allowed us to make conclusion that ecological problem and sustainable city development paradigm did not penetrate yet all social groups. The second factor covers $12 \%$ of variance for data that should be taken into account when the crowdshipping service will be deployed in Ukrainian cities. The third factor has been identified as "Store_lovers" covering $8.99 \%$ of variance. And the fourth factor was revealed as "Windows_shoppers". So, the third and the fourth factors reflect the people's intentions to remain shopping in the physical stores. The total variance covered by these two factors is $16.26 \%$. Summarizing we can say that crowdshipping has a high opportunity to be deployed in Ukrainian cities. To become widely used it should be grounded on flexible, reliable and ecologically friendly basis. Along with that the time saving should also be provided to compete with commercial delivery services.

Keywords: e-commerce, delivery system, crowdshipping, factor analysis. 